\title{
Investigating the Decision-Making Approach to Risk Assessment in Police Custody
}

\author{
Melanie-Jane Stoneman \\ Aeronautical and Automotive Engineering,Loughborough University, UK. E-mail: m.stoneman@lboro.ac.uk \\ Lisa Jackson \\ Aeronautical and Automotive Engineering, Loughborough University, UK.E-mail: l.m.jackson@lboro.ac.uk \\ Sarah Dunnett \\ Aeronautical and Automotive Engineering, Loughborough University, UK. E-mail: s.j.dunnett@lboro.ac.uk \\ Louise Cooke \\ School of Business and Economics, Loughborough University, UK. E-mail: l.cooke@lboro.ac.uk
}

When a person is booked into police custody in England and Wales they are assessed for risk of harm to themselves or to others. This risk assessment informs the decision as to what observation level they are placed on, ranging from hourly visits to constant observation for the highest risk detainees. In comparison to the international standard for risk management, there are gaps in the risk assessment process in police custody. Currently, the analysis and evaluation of identified risk is down to the experience and judgement of the Custody Officer, rather than a more structured method. This paper questions whether the process should be more formalized, using a statistical tool rather than relying on expert judgement. This paper uses a mixed methods approach investigating custody record data from three English police forces to identify key risk factors that lead to variances in observation levels, and interviewing sixteen Custody Officers from a further two forces investigating their perspective of the risk assessment process The findings suggest that whilst there are key factors affecting observation level, an entirely statistically based risk assessment process would lack the flexibility to account for the individual and would need to include additional information custody officers consider. It is concluded that further investigation should be conducted into a process which combines an actuarial approach with the intuitive insights gained from expert decision-making.

Keywords: Risk assessment, risk, decision-making, police custody, mixed methods.

\section{Introduction}

Risk is defined by the British Standard ISO 31000 as the "effect of uncertainty on objectives" (BSI, 2009, p2) and is often expressed in terms of likelihood of occurrence of an event and the impact of consequences from that event occurring. However, risk generally has negative connotations and can be further defined as 'the possibility of an unfortunate occurrence'(Society for Risk Analysis 2015).

Risk is a concern for all organizations, whether they are financial, engineering, environmental or human services. The assessment of risk is a crucial process carried out in order to identify and manage that possibility of occurrence. Guidance for risk management has been set out in BS ISO 31000 Risk management: principles and guidelines (BSI,

Proceedings of the 29th European Safety and Reliability Conference.

Edited by Michael Beer and Enrico Zio

Copyright (C2019 by ESREL2019 Organizers. Published by Research Publishing, Singapore

ISBN: 981-973-0000-00-0 :: doi: 10.3850/981-973-0000-00-0 esrel2019-paper
2009). This standard sets out the process of risk assessment, highlighting three key stages:

- Risk identification: finding and describing risks;

- Risk analysis: understanding the risk and determining the level based on consequences and likelihood;

- Risk evaluation: determining if the risk is acceptable or tolerable

The result of these three elements can then be used by the organization to identify the correct risk treatment strategy. This paper applies this standard to the process of risk assessment of detainees in police custody, identifying gaps and investigating how these gaps can be filled.

\subsection{Police custody}

In England and Wales, when booking a person into police custody, it is the responsibility of the Custody Officer (CO) to assess the level of risk 
2 M-J Stoneman, L. Jackson, S. Dunnett, and L. Cooke

of harm the detainee poses to themselves or to others.

National guidance provides questions that should be asked as part of this assessment, covering issues such as physical and mental ill health and previous self-harm (College of Policing 2017). In addition, COs also record their own observations about these and other relevant issues. Recent research has shown that in practice, the questions asked and observations recorded as part of this process varies greatly not only from this guidance, but also between police forces (Stoneman et al. 2018). The assessment of detainee risk then leads to a decision by the $\mathrm{CO}$ as to which support services need to be accessed, but also what observation level a detainee should be placed on. Observation levels vary from Level 1, a minimum of hourly visits to Level 4 close proximity, which is for detainees at the highest risk of harm and involves an officer or member of custody staff constantly observing the detainee (College of Policing 2017).

Figure 1 shows the risk assessment process as set out by the ISO (BSI, 2009, p14) compared to the risk assessment process in police custody.

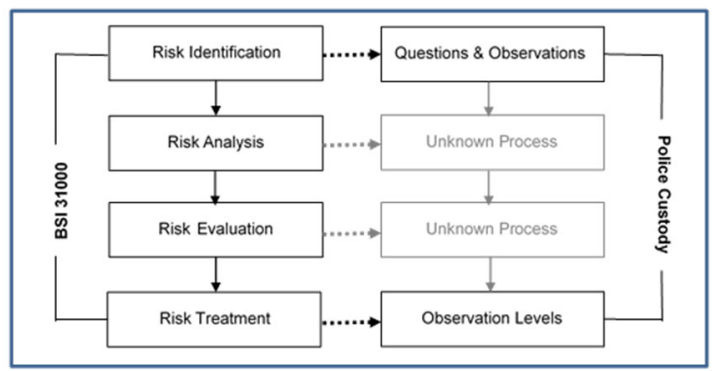

Figure 1. Comparison of risk assessment processes

Figure 1 demonstrates that although risk identification is carried out through questions and observations, there is little clarity as to how the $\mathrm{CO}$ then analyzes and evaluates the risk. Currently, this is based on the experience and knowledge of the $\mathrm{CO}$ leading to subjective decision-making, which is often complex and carried out in a demanding environment (McKinnon and Finch 2018).

\subsection{Decision making}

Decisions based on expert clinical judgement have generally found to be less accurate at prediction than actuarial or statistical methods (Meehl 1954, Doyle and Dolan 2002). Decision- making through clinical judgment can be criticised for being being informal and subjective, often with the experts misjudging correlations between variables leading to a lack of consistency (Dawes, Faust, and Meehl, 1989; Doyle and Dolan, 2002). However, methods based solely on statistical information and static indicators, have been criticized for their lack of ability to account for the individual, and for excluding expert judgement (Doyle and Dolan 2002, Slovic et al. 2004). Statistical models are not responsive and flexible enough to account for case-specific influences or rare events (Dawes, Faust, and Meehl, 1989; Doyle and Dolan, 2002), and research has shown that risk assessments based on statistical models are less likely to be adopted in human services (Doyle and Dolan 2002).

However, a third method has been proposed more recently in the form of structured clinical judgement. Structured clinical judgment is a method which aims to combine statistical tools with expert judgement, providing a framework for decision-making which offers consistency whilst providing flexibility to account for individuals (Doyle and Dolan 2002). Applying this in the police custody setting would provide a more structured way of analysing and evaluating detainee risk whilst appreciating the complex needs and lives of detainees.

\subsection{Contribution}

The work described in this paper seeks to bring new understanding to the decision-making process in police custody through interviewing the COs on how they judge detainee risk, alongside analysing custody record data to determine what key factors influence observation level. Recommendation on which type of decision-making process would be best suited to the custody process, to align the risk analysis and evaluation phases to ISO standards, is discussed with the suggestion that further research in the area should focus on a structured clinical judgement approach.

\section{Methodology}

This paper uses a mixed methods approach to investigate the process of risk assessment of detainees within police custody. Qualitative research has been undertaken through interviews with COs to try and understand the process they go through and what informs their decision 
Investigating the Decision-Making Approach to Risk Assessment in Police Custody

making. Custody record data has been analyzed quantitatively to identify the risk factors that have the most influence on the observation level set. A mixed method approach enables the findings from both the qualitative and quantitative analysis to be triangulated, providing a more holistic view of the process (Berg 2006). Although findings from qualitative analysis are not statistically robust, they can provide an increased understanding of the situation (Flick 2007a). Qualitative analysis helps to identify the 'why' and 'how' of a phenomenon, something that is not always identifiable through quantitative analysis alone, particularly when examining human decisionmaking.

\subsection{Qualitative Analysis}

The format of the interviews with the COs was semi-structured using an interview guide as an aide. This provided not only a framework to allow for comparisons but also a level of flexibility in the flow of the interview (Flick 2007b). The theoretical approach of the researcher was of a constructivist worldview in that there was no pre-defined theory to the research and the aim was to understand the situation - risk assessment of detainees, from the point of view of the participants - the COs (Creswell 2014).

\subsubsection{Semi-structured interviews}

Interviews were carried out at two custody suites in two police forces using an interview guide which focused on the risk assessment of detainees at the booking-in stage. Both forces cover a large population and, in both cases, the main custody suite where the interviews took place was situated in an inner city. Both forces use the custody record management system NICHE and are therefore provided with similar risk assessment questions to ask detainees.

Overall, 16 Custody Officers were interviewed over a three-month period from September to November 2018. It should be noted that there were differences between the two forces working policies within custody which may have influenced the perspective of the CO. For example, Force $\mathrm{B}$ had a rotation policy which meant that there was a maximum number of years that Officers could spend working in custody. This policy was not present in Force A. This meant that the average length of time in custody for the interviewed COs varied between Force A (7.5 years) and Force B (1.1 years) which may have impacted their approach to risk assessment.

\subsubsection{Interview analysis}

Analysis of interviews was undertaken using a thematic approach, where a theme was defined as a distinct, re-occurring pattern in the interviews which related to the research question (King, Horrocks, and Brooks 2019) of how a CO judges' detainee risk and how they identify which observation level should be allocated. Coding was carried out in NVivo 11 (QSR 2015) and was based on a mixture of predetermined codes established from the interview guide; and codes that emerged out of the interviews themselves. These codes were then grouped into overarching themes, providing a two-level hierarchical structure as shown in Table 1.

Table 1. List of themes and sub themes extracted from Custody Officer interviews

\begin{tabular}{|c|c|}
\hline Theme & Sub Theme \\
\hline Visual Cues & $\begin{array}{l}\text { Presentation \& Engagement } \\
\text { Body Language }\end{array}$ \\
\hline External Sources & $\begin{array}{l}\text { IT Systems } \\
\text { Arresting Officers } \\
\text { Healthcare Professionals }\end{array}$ \\
\hline Use of Questions & $\begin{array}{l}\text { Adapting \& Probing } \\
\text { Cross-Checking }\end{array}$ \\
\hline Judgement & $\begin{array}{l}\text { Experience } \\
\text { Gut Instinct } \\
\text { Combining Information }\end{array}$ \\
\hline Risk Factors & $\begin{array}{l}\text { Alcohol } \\
\text { Offense } \\
\text { First time in custody } \\
\text { Mental \& physical health }\end{array}$ \\
\hline
\end{tabular}

\subsection{Quantitative analysis}

Custody record data pertaining to demographics, offense and risk assessment was collected from three different police forces, two of which also used the NICHE custody record system. The records were analyzed with the aim of discovering the most influential factors in determining observation level. Univariate and multivariate analysis was carried out using IBM Statistics 23 (IBM Corp. Released 2015). 
4 M-J Stoneman, L. Jackson, S. Dunnett, and L. Cooke

\subsubsection{Custody record data}

The custody record data contained 259 records and covered the six-month period from January to June 2016. Data collected included the initial observation level (dependent variable) along with 23 independent variables, as shown in Table 2. Univariate analysis was conducted to identify variables with a significant association to Observation Level. For categorical variables the Chi Square Test for Association was used and for continuous variables, Analysis of Variance was calculated. The variables with a significant association to Observation Level are also identified in Table 2 and were included in the multivariate analysis stage.

Table 2. Independent variables included in the custody record data

\begin{tabular}{ll}
\hline Category & Variable \\
\hline Demographic \& & Gender \\
Socio-economic & Age* \\
& Ethnicity* \\
& Employment \\
\hline Offense & Offense type \\
& Arrival time \\
& Day of week \\
\hline Detainee reported & Current illness or injury* \\
risks & Medical history* \\
& Mental health problems* \\
& Self-harm* \\
& Current feelings* \\
& Drug use* \\
& Alcohol use* \\
& Substance dependency \\
& Alcohol dependency \\
\hline Custody Officer & Straight to cell \\
observations & First time in custody* \\
& Current illness or injury* \\
& Self-harm* \\
& Alcohol influence* \\
& Drug influence* \\
& Behaviour / demeanor* \\
& Restraint use* \\
\hline
\end{tabular}

* Indicates variables that had a significant association with Observation Level

Three multivariate analysis methods were used for comparison: discriminant analysis (DA), logistic regression (LR) and decision trees (DT). These analysis methods were chosen for their ability to categorize and predict a dependent variable, Observation Level, based on a set of independent variables. DA does this by calculating a discriminant function through maximising between group variance relative to within group variance. LR maximizes the joint likelihood of the data and estimates regression coefficients that predict the probability of the outcome of interest. In comparison, DT's recursively partition the target variable into subgroups based on the most significant link between the independent and dependent variables. The results from the three models were then compared to identify a core set of variables that affected observations level. A more detailed explanation of the methodology can be found in Stoneman et al. (2019).

\section{Findings}

\subsection{Qualitative Analysis}

When analyzing the interview data in terms of how COs judge detainee risk and determine observation level, five key themes became apparent: visual cues; information from external sources; identification of risk factors; how the questions on the risk assessment proforma are used; and judgement. This section investigates these themes further.

\subsubsection{Visual Cues}

In response to being asked how the $\mathrm{CO}$ would judge what level of observation they should be on, many COs talked about visual cues such as the body language of the detainee, how the detainee presented and how well the detainee engaged with them. This is demonstrated through the following quotes:
"It's looking at the answers that are given but then it's also the way that they've answered that, and their body language, so it's not only what they're saying but it's how they're saying it, and again you can gauge that before you've even spoken to somebody" Int 2
“And while I'm speaking to them and they're answering, I'm also looking at their demeanor, I'm looking at how they're answering. Can I smell intoxicants on their breath? Are they unsteady on their feet? I look at their pupils to see if they're dilated. So I'll take into consideration all of these different factors..." Int 13.




\subsubsection{External information sources}

In addition to the questions posed to detainees, COs will also consult external sources for information on the detainee in terms of risk. For example, most of the COs interviewed talked about accessing the detainee's records on the Police National Computer (PNC) or previous custody records on their own system in order to see if there were any warning markers for the detainee, or if the detainee was non-compliant, to look at previous risk assessments to help them form an opinion on observation level.

“...and also warning markers we put within our own system, and also we can also go back into previous custody records, so lots of the people we deal with are in regularly, so you can see how they are dealt with previously, so often people come in and they're intoxicated and not in a position to answer the questions so you can always look back and see if they've got any issues that we need to be concerned about." Int 5

In addition, several of the COs referred to gaining information from the arresting officers:

\begin{abstract}
"Speaking to the officers, what are the circumstances here? Because quite often when they're brought into... or when they're arrested the officers will speak to friends, family and they will tell them information that the detained person may not want to disclose at the desk. So it's about talking to the officers as well before you speak to the detainee to see what information they hold about the person you're about to book in." Int 15
\end{abstract}

And some COs would approach the healthcare professionals for their opinion if they were unsure:

“...but if I've got some serious concerns then during the booking-in process if the healthcare professional is free, I'll just ask them to sit in and watch while we do the booking-in process, so I can get their observation and then between us we can make a decision as to what's going to happen" Int 13
3.1.3 Identification of risk factors

As well as identifying risks factors that are covered by the risk assessment questions, such as mental health, self-harm and injuries and illnesses, when interviewed the COs also discussed other factors that may increase the risk of harm to or by the detainee and would therefore lead to a more frequent observation level. This included the nature of the offense, particularly where the impact on the detainee's personal life may be large.

"Nature of offense. Simple things like drink driving. Simple offense, never been in custody before but to that person it can be the end of the world. Their driving license is going to go, they might need that for their job. How are they going to pay the mortgage? The kids. So sometimes I go on what offense it is " Int 10

Also, whether the detainee had been in custody before was seen as a risk factor, particularly if it was their first time:

"The worry is the person who hasn't been in before, who doesn't want to press that button, because he doesn't want to interact with you and are just stuck there in their own shell with all sorts of unknown problems that they're not telling you" Int 12

The risk of a detainee going into withdrawal from alcohol was also raised in many of the interviews, with COs stressing how risky that situation is to the safety of the detainee:

"I would say the alcohol one is the biggie because an alcoholic will die if they don't get treated" Int 7

\subsubsection{Use of risk assessment questions}

In discussing the risk assessment proforma with COs it became apparent that often COs would use the set questions as a framework to probe deeper into the issues, adapting the questions where needed and cross-checking the information that the detainees provided with other sources of information such as previous custody records.

"It's about probing the answers that they give you to come to the conclusion around what obs that you're going to put them on" Int 15 
6 M-J Stoneman, L. Jackson, S. Dunnett, and L. Cooke

"Digging a little bit deeper if... I suppose for a personal understanding as well. If I don't really understand what you're telling me, a load of drugs you're taking - what are they for? Because I don't know what they're for. So, explain to me, help me understand how I can look after you" Int 16

"Some Sergeants will read the question verbatim. After a certain amount of time, you just get a bit more fluid with it and whilst you're booking someone in you can be asking them those questions a bit more casually." Int 11

\subsubsection{Judgement}

When discussing how the COs judged what observation level the detainee should be placed on, quite often the interviewees would refer to "experience" and "gut instinct" as demonstrated by the following quotes:

"I think you possibly get a bit of a knack of which level to put someone on with a bit of experience" Int 4

"you've got to have guidelines which you need to adhere but then also you've got to use your professional knowledge haven't you? ” Int 7

"But I think generally, it's mainly down to the custody sergeants gut instinct and what they feel" Int 14.

\subsubsection{Summary}

These findings suggest that although the risk assessment questions on the system are useful they only form part of the assessment and in practice a variety of information is considered, from historical records to visual cues to the tacit knowledge and experience of the CO. This can be summed up by the following quote:

"And it's kind of an amalgamation of all those things - the NICHE warning signals, the PNC warning signals, the offending history, the nature of the offense, the specific questions I've asked, the way they're presenting and then I kind of, though many years of experience, I've put all that together, I'll come out at a judgement as to how, what sort of level I think they... is appropriate" Int 6.

\subsection{Quantitative Analysis}

\subsubsection{Multivariate Analysis}

The independent variables identified through univariate analysis as having a significant association with Observation Level, as shown in Table 2, were included in the multivariate analysis. However, not all of these variables were shown to be statistically significant in the multivariate models. All three multivariate analysis methods were able to produce a classification model which correctly predicted a relatively high proportion of cases, as shown in Table 3.

Table 3. Proportion of cases correctly predicted by Method and Observation Level

\begin{tabular}{lrrr}
\hline $\begin{array}{l}\text { Observation } \\
\text { Level }\end{array}$ & DA & LR & DT \\
\hline 60 mins & $31.4 \%$ & $25.0 \%$ & $68.6 \%$ \\
30 mins & $86.2 \%$ & $88.7 \%$ & $72.8 \%$ \\
15 mins + & $72.1 \%$ & $74.6 \%$ & $77.0 \%$ \\
Overall & $72.0 \%$ & $73.1 \%$ & $73.0 \%$
\end{tabular}

In general, there was less ability to predict the lowest observation level than the higher observation levels. However, overall all three models were able to correctly predict $>72 \%$ of cases. The independent variables included in these prediction models are displayed in Table 4.

Table 4. Independent variables included in the three modelling methods

\begin{tabular}{llll}
\hline Variable & DA & LR & DT \\
\hline Day of week & $\checkmark$ & & $\checkmark$ \\
$\begin{array}{l}\text { First time in custody } \\
\text { Observed alcohol }\end{array}$ & $\checkmark$ & & \\
influence & $\checkmark$ & $\checkmark$ & $\checkmark$ \\
$\begin{array}{l}\text { Observed behaviour / } \\
\text { Demeanor }\end{array}$ & $\checkmark$ & & $\checkmark$ \\
$\begin{array}{l}\text { Observed self-harm } \\
\text { Offense type }\end{array}$ & $\checkmark$ & $\checkmark$ & $\checkmark$ \\
$\begin{array}{l}\text { Reported alcohol use } \\
\text { Reported drug use }\end{array}$ & $\checkmark$ & $\checkmark$ & $\checkmark$ \\
$\begin{array}{l}\text { Reported current } \\
\text { feelings }\end{array}$ & & $\checkmark$ & $\checkmark$ \\
$\begin{array}{l}\text { Reported current } \\
\text { injury or illness }\end{array}$ & $\checkmark$ & $\checkmark$ & \\
$\begin{array}{l}\text { Reported mental } \\
\text { health problems }\end{array}$ & $\checkmark$ & $\checkmark$ & $\checkmark$ \\
$\begin{array}{l}\text { Reported self-harm } \\
\text { Restraint used }\end{array}$ & $\checkmark$ & & \\
\hline
\end{tabular}


Investigating the Decision-Making Approach to Risk Assessment in Police Custody

Table 4 shows a number of independent variables that appear in all three multivariate models: Observed Alcohol Intoxication, Reported Alcohol Use, Reported Drug Use and Reported Mental Health issues. In addition several variables appear in two of the three models: Day of Week, Observed Demeanor, Offense, Reported Feelings and Reported Injury or Illness.

\subsubsection{Summary}

These findings suggest that quantitatively, there are a core group of variables that influence the initial observation level set by the CO. Whilst this does not comment on how accurate the Observation Level chosen is in relation to the risk, it does suggest that CO's weight these variables more than others in their decision of Observation Level. Therefore, if an actuarial risk assessment tool was developed, these factors should be considered for inclusion.

\section{Discussion}

Analysis of detainee risk assessment through custody record data identified a core group of variables that impacted on the observation level set by the CO. These variables covered issues such as alcohol and drug use, mental health, offense, demeanor and current feelings, injury or illness and day of week. It should be noted that these findings do not comment on the ability of the variables to accurately assess risk, only on their influence on which Observation Level is chosen. Further research should be conducted to investigate the correlation between risk and the presence of these factors.

It is interesting to note that alcohol, especially risk of alcohol withdrawal was a key topic that came out of the interviews with COs, even more so than drug use. In addition, $\mathrm{COs}$ often mentioned the type of offense as being a risk factor, particularly due to the impact of the situation on the detainee's life. Demeanor and current feelings of the detainee were often mentioned in interviews as one of the main risk factors, with COs often placing a lot of weight on how the detainee presented and engaged with the custody officer. In contrast, day of week was not really identified as a risk factor during interviews other than in mentioning that weekends could be busier, particularly with drunk detainees, which would have an impact and pressure on resources.
A key finding through the interviews is that COs base their judgement of risk and allocation of observation level on a complex combination of factors which are not all quantifiable. The questions asked to the detainee as part of the risk assessment were identified to be useful in order to pick up on relevant issues, however it was the probing of these issues and the supplementary questions asked which provided the important contribution to the process and would vary depending on the individual. Similarly, the structured observations made as part of the risk assessment were useful in providing the $\mathrm{CO}$ with a space to input contradictory information to what the detainee had said, however the COs often mentioned "gut instinct" or "getting a feeling" for someone without being able to explain why.

In addition to this, the COs reported using external information to help them in their decision-making. Often, before they had even seen the detainee, COs consult databases for historic information on the detainee, either in the form of warning markers or previous risk assessments, as well as speaking to the arresting officer to get their assessment of the risk and any information they may have gained from family and friends. COs also cited having access to healthcare professionals as an informing element to the risk assessment, especially if the HCP was present on booking-in the detainee.

\section{Conclusion}

The inclusion of not only external data, but also the gut instinct of the Custody Officer suggests that a purely statistically created risk assessment tool based on the current risk assessment questions would not capture all the information needed for the risk assessment of the detainee. As many of the Custody Officers highlighted, they are dealing with individuals who may have complex needs and who may or may not inform the Custody Officer of these. However, if the risk assessment is to become more robust in the analysis and evaluation stages, as set out in the ISO, there also needs to be a more structured process. Therefore, it is suggested future research should investigate the possibility of using a structured clinical decision approach to detainee risk assessment in police custody bringing together expert judgment and statistical evidence in the decision-making process. 
8 M-J Stoneman, L. Jackson, S. Dunnett, and L. Cooke Acknowledgement

This work was supported by the EPSRC under Grant EP/M507908/1

\section{References}

Berg, B. (2006). Qualitative research methods for the social sciences. 6th ed. Pearson/Allyn \& Bacon.

British Standards Institute (2009). BS ISO 31000:2009 - Risk management: Principles and guidelines. British Standards Institute Ltd

College of Policing. (2017). Detention and Custody Authorised Professional Practice. College of Policing. http://www.app.college.police.uk/appcontent/detention-and-custody-2/.

Creswell, J. (2014). Research design : qualitative, quantitative, and mixed methods approaches. $4^{\text {th }}$ ed, SAGE.

Dawes, M., Faust, D., and Meehl, P. (1989) Clinical versus actuarial judgement. Science 243 (4899) $1668-1673$

Doyle, M., and M. Dolan. (2002). Violence risk assessment: combining actuarial and clinical information to structure clinical judgements for the formulation and management of risk. Journal of Psychiatric and Mental Health Nursing 9 (6), 649-657.doi: 10.1046/j.1365-2850.2002.00535.x.

Flick, U. (2007a). Managing quality in qualitative research, The Sage Qualitative Research Kit. Sage Publications Ltd.

Flick, U. (2007b). Designing qualitative research, The SAGE Qualitative Research Kit. Sage Publications Ltd.

IBM, SPSS Statistics for Windows, Version 23.0. IBM

Corp.

King, N., C Horrocks, and J. Brooks. (2019). Interviews in Qualitative Research. 2nd ed. Sage Publications Ltd.

McKinnon, I., and T. Finch. (2018). Contextualising health screening risk assessments in police custody suites - qualitative evaluation from the HELP-PC study in London, UK. BMC Public Health 18:13. doi: 10.1186/s12889-018-5271-6.

Meehl, P. (1954). Clinical versus statistical prediction: a theoretical analysis and a review of the evidence: Minnesota U.P.

QSR. NVivo qualitative data analysis Software 11. QSR International Pty Ltd.

Slovic, P, M. Finucane, E Peters, and D. Macgregor. (2004). Risk as Analysis and Risk as Feelings: Some Thoughts about Affect, Reason, Risk, and Rationality. Risk Analysis 24 (2), 311-322. doi: 10.1111/j.0272-4332.2004.00433.x.

Society for Risk Analysis. (2015). Society for Risk Analysis Glossary. Society for Risk Analysis.

Stoneman, M-J., L. Jackson, S. Dunnett, and L. Cooke. (2019). Enhanced understanding of risk assessment in police custody in England and 